\title{
MONITORING MINIMAL RESIDUAL DISEASE IN CANINE LYMPHOMAS TREATED WITH MODIFIED L-COP OR L-CHOP PROTOCOLS
}

\author{
Sirintra SiRIVISOOT ${ }^{1}$, Patharakrit TEEWASUTRAKUL ${ }^{2}$, Somporn TECHANGAMSUWAN ${ }^{1}$, \\ Sirikachorn TANGKAWATTANA ${ }^{3}$ and Anudep RUNGSIPIPAT ${ }^{1 *}$ \\ ${ }^{1}$ Companion Animal Cancer Research Unit, Department of Pathology, Faculty of \\ Veterinary Science, Chulalongkorn University, Bangkok 10330, Thailand; ${ }^{2}$ Oncology \\ Clinic, Small Animal Teaching Hospital, Faculty of Veterinary Science, Chulalongkorn \\ University, Bangkok, Thailand; ${ }^{3}$ Department of Veterinary Pathobiology, Faculty of \\ Veterinary Medicine, Khon Kaen University, Khon Kaen, Thailand
}

(Received 30 May 2017; accepted 6 November 2017)

\begin{abstract}
Heteroduplex polymerase chain reaction for antigen receptor rearrangements (hPARR) was developed to monitor minimal residual disease (MRD) in canine B- and T-cell lymphomas treated with the modified L-COP or L-CHOP protocol. Thirty-five dogs were recruited in this study and their neoplastic lineages were determined by immunophenotyping with Pax 5 and CD3. Peripheral blood leukocytes were collected prior to and during chemotherapy in weeks 4, 9 and 13 to detect MRD by hPARR. Twenty-eight dogs (80\%) had B-cell lymphoma while seven dogs $(20 \%)$ had T-cell lymphoma. A monoclonal band was detected in 11 cases that showed complete or partial remission before tumour relapse and no response to the current treatment without statistical difference in clinical outcomes; however, the treatment response had an association with the MRD result $(\mathrm{P}<0.05)$. Modified L-CHOP prolonged median progression-free survival as compared to modified L-COP $(215$ days vs. 93 days; $\mathrm{P}<0.05)$. Substage $\mathrm{b}$ had shorter progression-free survival than substage a (90 days vs. 215 days; $\mathrm{P}<0.05)$. Clinical stage III affected median overall survival time when compared to clinical stages IV and V (432, 173 and 118 days, respectively; $\mathrm{P}<$ 0.05 ). hPARR could be used for screening refractory lymphoma together with lymph node measurement in routine clinical cases.
\end{abstract} PARR

Key words: Chemotherapy, dog, lymphoma, minimal residual disease,

Minimal residual disease (MRD) is a remnant of neoplastic cell that survives during or after chemotherapeutic treatment. It can be an indicator of tumour relapse and treatment outcome. Because of a low level of malignant cells during clinical remission, they should be monitored by advanced sensitive mo-

"Corresponding author; E-mail: Anudep.R@chula.ac.th; Phone: 0066 (2) 218-9620; Fax: 0066 (2) 252-0779 
lecular methods, such as PCR, real-time PCR or flow cytometry (Calzolari et al., 2006; Yamazaki et al., 2008; Gentilini et al., 2013; Aresu et al., 2014). If the quantity of MRD in patients was increased during or after treatment, this indicated poor prognosis and inadequate treatment efficacy in human and canine lymphomas (Yashima et al., 2003; Pott et al., 2006; Sato et al., 2013).

Polymerase chain reaction for antigen receptor rearrangements (PARR) is a molecular technique that detects alleles of immunoglobulin heavy chain $(\mathrm{IgH})$ and T-cell receptor gamma (TCR $\gamma$ ) genes, the antigen-binding receptors of B and $\mathrm{T}$ lymphocytes, respectively. This technique showed a high sensitivity for detecting clonal B- or T-cell populations from various types of samples in dogs (Burnett et al., 2003). Because neoplastic lymphocytes could circulate in blood, peripheral blood is a good sample source for MRD screening (Keller et al., 2004; Lana et al., 2006; Thilakaratne et al., 2010). Aresu et al. (2014) compared the suitability of the flow cytometry and PARR methods to assess MRD in peripheral blood, lymph node (LN), and bone marrow samples in canine high-grade Bcell lymphoma. They found that PARR had higher sensitivity than flow cytometry from peripheral blood. Moreover, the MRD-positive cases screened by PARR showed a correlation with the time of relapse. In addition, dogs in which MRD was detected after complete remission had a shorter survival time than other dogs that were free of MRD (Manachai et al., 2012). Therefore, monitoring MRD might be a useful method for detecting refractory canine lymphoma.

Heteroduplex analysis with PARR (hPARR) was recommended for the diagnosis of canine lymphoma because it decreased the chance of misdiagnosis due to pseudoclonality (Takanosu et al., 2010). After denaturation and slow reannealing, it helped the formation of homoduplex molecules with identical size and sequence, and rendered defective the re-annealing of heteroduplex molecules with identical size and different sequence. Homogenous PCR products then migrated in expected size and showed the monoclonal band in high-resolution gel, while heterogeneous products migrated slowly, leading to a diffuse smear pattern. This increased the specificity of interpretation of PCR amplicons and validation of the clonal results.

The recommended chemotherapy for canine lymphomas is a L-CHOP protocol (L-asparaginase, vincristine, cyclophosphamide, doxorubicin, and prednisolone) (Garrett et al., 2002). However, a high-dose COP treatment (vincristine, cyclophosphamide, and prednisolone) might be one option because it has a lower cost (Dobson et al., 2001). Multicentric lymphoma treated with a COP combination with L-asparaginase (L-COP) or without L-asparaginase showed a complete remission rate of $70-80 \%$ and had median survival times of 6-7 months (Dobson et al., 2001; Jeffreys et al., 2005). However, this treatment has a longer maintenance phase, and shorter progression-free survival (PFS) and overall survival time (OST). On the other hand, the maintenance-free L-CHOP treatment has an 
overall response rate of $90-100 \%$ and a prolonged OST of 12 months (Garrett et al., 2002; Burton et al., 2013; Curran and Thamm, 2016).

Although canine lymphoma is responsive to chemotherapy, it could be resistant to antineoplastic drugs due to multidrug-resistance genes (Zandvliet et al., 2015). LN size evaluation used concurrently with an adjunctive molecular tool might provide a tumour burden in non-target lesions other than peripheral lymph nodes. The purposes of this study were to monitor MRD in canine B- and T-cell lymphomas treated with the modified L-COP (mL-COP) or modified L-CHOP (mL-CHOP) protocols by hPARR, and to evaluate the efficacy of treatment. The clinical outcomes were correlated with the chemotherapeutic protocols, immunophenotype, clinical stage, substage and MRD results.

\section{Materials and methods}

\section{Animals and sample collections}

Thirty-five dogs had been sent to the Oncology Clinic, Small Animal Teaching Hospital, Chulalongkorn University in 2013 through 2015 (IACUC Number 13310074). They were clinically diagnosed as having multicentric lymphoma by cytopathology and/or histopathology according to the WHO criteria. All dogs were checked for complete blood count (CBC), liver enzymes (alanine aminotransferase, ALT and alkaline phosphatase, ALP), and kidney function [blood urea nitrogen (BUN), creatinine, total protein, albumin and globulin]. The dogs were examined for blood parasites using thin blood smears and by testing the presence of serum antigen of heartworm (Dirofilaria immitis), serum antibody against Ehrlichia canis and Anaplasma platys using the SNAP 4Dx Plus Test kit (IDEXX, USA). Clinical staging was done on the basis of CBC, thoracic and abdominal radiographs, abdominal ultrasound for detecting liver and spleen metastasis, and buffy-coated smears for leukaemia assessment. After immunophenotyping, the dogs received the $\mathrm{mL}-\mathrm{COP}$ or $\mathrm{mL}-\mathrm{CHOP}$ protocol (Table 1) depending on the owner's decision and the dogs' cardiac condition. Peripheral blood was collected into an EDTA tube in week 0 and during the treatment in weeks 4, 9 and 13. Dogs treated with $\mathrm{mL}-\mathrm{CHOP}$ received a 25 -week protocol while those treated with $\mathrm{mL}$-COP received a 1-year protocol. After achieving a complete remission, the animals were followed up monthly or bimonthly. Physical examination was performed and $\mathrm{CBC}$ as well as hepatic and renal chemistry profiles were checked before giving antineoplastic drugs. If patients had abnormal blood results, such as leukopenia, anaemia, increased hepatic or renal values, the chemotherapy was postponed until the adverse events were normalised, and until that time they received only supportive treatment. 


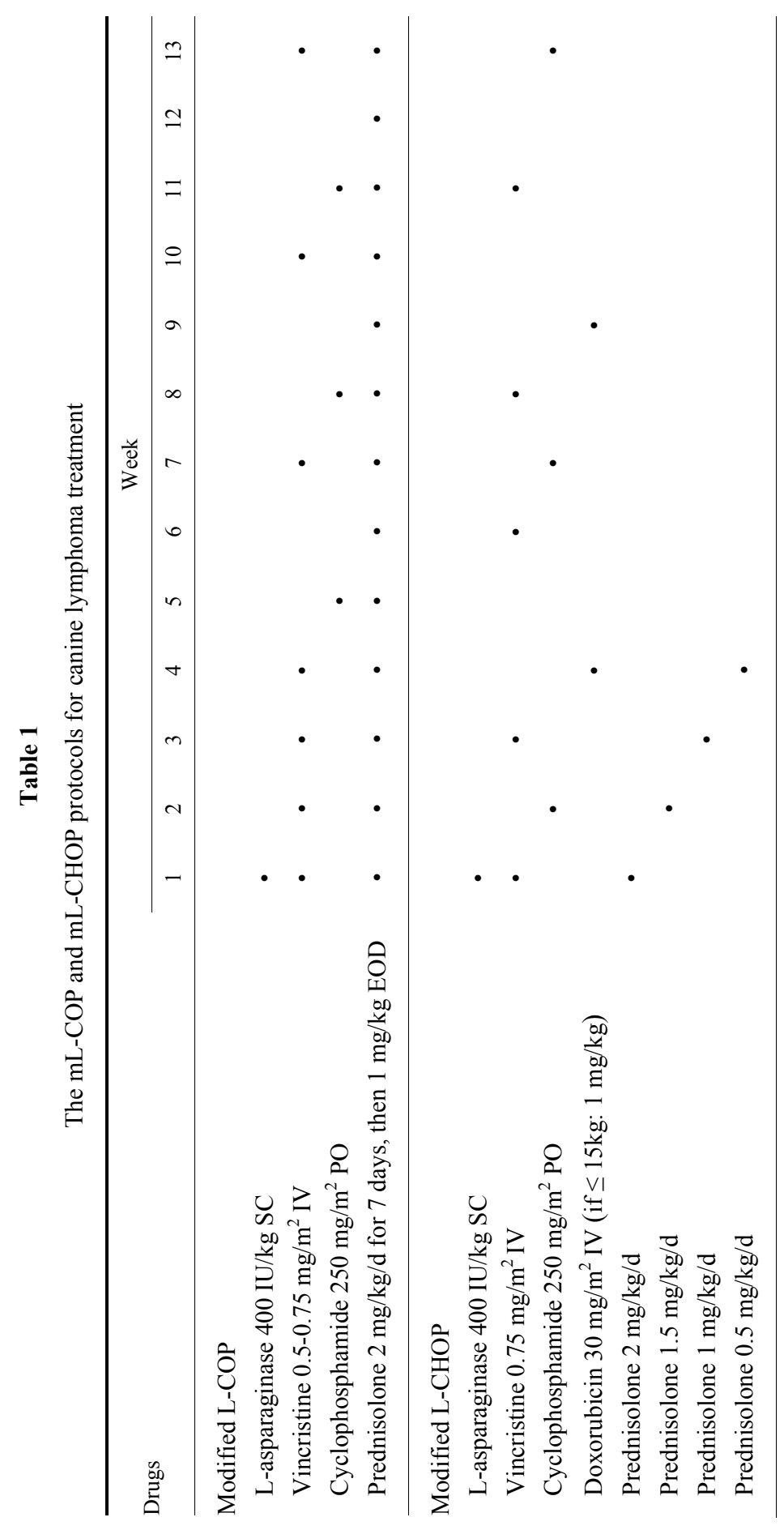




\section{Cytopathology/histopathology}

Cytological specimens were collected by fine needle aspiration from enlarged superficial LNs in those cases that were unsuitable for general anaesthesia and biopsy procedures. Four cytological smear slides were prepared for cytopathological classification based on Updated Kiel (Sapierzynski et al., 2010), stained by Giemsa, and for immunocytochemistry, immunostained by Pax 5 and CD3. For the histopathological study, a punch biopsy of $6 \mathrm{~mm}$ diameter was applied to collect samples from enlarged superficial nodes, and the biopsy sample was kept in $10 \%(\mathrm{w} / \mathrm{v})$ neutral buffered formalin. Routine histological processing and paraffin wax embedding were performed. Four- to $6-\mu \mathrm{m}$-thick sections were stained with haematoxylin and eosin (HE) for histopathological classification based on the WHO criteria (Valli et al., 2011), and immunostained with Pax5 and CD3 for immunophenotyping.

\section{Immunocytochemistry (ICC)}

After fixing the slides with cold acetone for $10 \mathrm{~min}$, they were kept at $-20{ }^{\circ} \mathrm{C}$ until used. In brief, cells on the glass slide were blocked for endogenous peroxidase and protein background by $3 \%(\mathrm{v} / \mathrm{v}) \mathrm{H}_{2} \mathrm{O}_{2}$ and $1 \%(\mathrm{w} / \mathrm{v})$ bovine serum albumin (Merck Millipore, USA) in $0.25 \%$ phosphate-buffered salineTriton X-100 (PBST), followed by incubation with the monoclonal mouse antihuman Pax5 antibody (1EW; Leica, USA) at a dilution of $1: 50$ at $4{ }^{\circ} \mathrm{C}$ for $12-$ $14 \mathrm{~h}$. For T-cell detection, cells were treated as B cells above except for using the ready-to-use monoclonal mouse anti-human CD3 antibody (LN10; Leica, USA). In both cases the signal of the bound antibody was amplified by Novolink polymer (Leica, USA) for $15 \mathrm{~min}$ and colour was developed with by 3,3'diaminobenzidine (DAB; Leica). Slides were counterstained with Mayer's haematoxylin for $1 \mathrm{~min}$. Cytological smears from normal canine LN were used as negative control. Pax5 showed a nuclear staining in B cells while CD3 showed immunoreactivity in the cytoplasm of T cells. B-cell or T-cell lymphomas were identified if at least $60 \%$ of the cells revealed expression of Pax 5 or CD3, respectively (Sirivisoot et al., 2017).

\section{Immunohistochemistry (IHC)}

In the case of Pax5, antigens were revived by treatment of the slides in Tris/EDTA (pH 9.0) in an autoclave oven $\left(121^{\circ} \mathrm{C}\right)$ for $5 \mathrm{~min}$, while for $\mathrm{CD} 3$ the antigen was retrieved by heating the slides with $10 \mathrm{mM}$ citrated buffer (pH 6.0) in a microwave for 6 min twice. Subsequently, the slides were blocked, incubated with the relevant monoclonal mouse anti-human antibody, and processed as described for ICC above. A normal canine lymph node obtained from necropsy was used as a staining control. Interpretations of positive B-cell or T-cell lym- 
phomas were achieved when at least $60 \%$ of the neoplastic cells stained positive with Pax5 and CD3, respectively (Sirivisoot et al., 2017).

\section{MRD by $h P A R R$}

The EDTA-anticoagulated blood was centrifuged at 5,000 rpm for $5 \mathrm{~min}$ and the peripheral blood leucocytes were separated and kept at $-20{ }^{\circ} \mathrm{C}$ for DNA extraction. Genomic DNA was extracted using a mammalian genomic DNA miniprep kit (Sigma-Aldrich, USA) and the obtained DNA concentration was measured by NanoDrop Lite spectrophotometer (Thermo Fisher Scientific, USA). Samples were then analysed for IgH and TCR $\gamma$ genes by hPARR (Takanosu et al., 2010) using the four primer sets in Table 2: the $\mathrm{C} \mu$ gene as a control for DNA amplification (Burnett et al., 2003), the IgH gene of B lymphocytes (Tamura et al., 2006) and two TCR $\gamma$ gene primer pairs for T lymphocytes (Yagihara et al., 2007). The DNA and primer concentrations were 50-200 ng and 200-300 nM, respectively. The PCR was thermocycled with 35 cycles of $94{ }^{\circ} \mathrm{C}$ for $45 \mathrm{sec}$, $60{ }^{\circ} \mathrm{C}$ for $30 \mathrm{sec}$, and $72{ }^{\circ} \mathrm{C}$ for $30 \mathrm{sec}$. After conventional PARR, each PCR product was divided into two aliquots and one was run for heteroduplex analysis by incubation at $95{ }^{\circ} \mathrm{C}$ for $5 \mathrm{~min}$ and re-annealing at $4{ }^{\circ} \mathrm{C}$ for $30 \mathrm{~min}$. Afterwards the PCR products were resolved by $2 \%(\mathrm{w} / \mathrm{v})$ agarose gel electrophoresis and visualised with $10 \%(\mathrm{w} / \mathrm{v})$ ethidium bromide staining by Alphamanager ${ }^{\mathrm{TM}}$ (Alpha Innotech, USA). DNase-/RNase-free distilled water was used in place of the template as a negative control. ExcelBand $100 \mathrm{bp}+3 \mathrm{~K}$ DNA ladder (Smobio Technology, Taiwan) was used for sample size identification. A monoclonal or biclonal band of each gene indicated hPARR positivity, whilst the presence of a polyclonal band or no band was regarded as hPARR negative. Biopsy samples diagnosed as B- and T-cell lymphomas were used as B- and T-cell positive controls.

Table 2

Primer sets used in the hPARR method

\begin{tabular}{lclc}
\hline Product & Primer names & \multicolumn{1}{c}{ Primer sequence (5'-3') } & Product size \\
\hline $\mathrm{C} \mu$ & Sigmf1 & TTC CCC CTC ATC ACC TGT GA & $130 \mathrm{bp}$ \\
& Sr $\mu 3$ & GGT TGT TGA TTG CAC TGA GG & \\
\hline IgH & V region & ACA CGG CC(A/C/G) TGT ATT ACT GT & $80-150 \mathrm{bp}$ \\
& J region & TGA GGA GAC GGT GAC C & \\
\hline TCR $\gamma$ & V $\gamma \mathrm{a}$ & CGT GTA CTA CTG CGC TGC CTG G & $55-90 \mathrm{bp}$ \\
& V $\gamma \mathrm{b}$ & GGC TGT ATT ACT GTG CCT GCT GG & \\
& J $\gamma \mathrm{b}^{\mathrm{a}}$ & TGT GCC AGG ACC AAG CAC TTT GTT & \\
& &
\end{tabular}

${ }^{\mathrm{a}}$ Primer $\mathrm{J} \gamma \mathrm{b}$ was used with either V $\gamma \mathrm{a}$ or $\mathrm{V} \gamma \mathrm{b}$ 
Follow-up of cases

Peripheral LN measurements (target lesions: submandibular, prescapular, superficial inguinal and popliteal LNs) using callipers were recorded to assess treatment efficacy: complete response (CR; disappearance of all target lesions), partial response (PR; at least 30\% decrease in the sum longest diameter of target lesions), stable disease (SD; target lesions showing neither sufficient decrease for PR nor sufficient increase for PD), and finally progressive disease (PD; at least $20 \%$ increase in the sum longest diameter of target lesions) (Vail et al., 2010). If dogs showed PD and/or hPARR positivity during the treatment in weeks 4, 9, and 13 (refractory lymphoma), they received a rescue drug, such as lomustine or L-asparaginase with vincristine. Dogs with a complete treatment were followed up every one or two months. Each case was noted for PFS and OST.

\section{Statistical analysis}

PFS and OST were compared by Kaplan-Meier survival analysis between $\mathrm{B}$ - and T-cell originated lymphomas that were treated with the $\mathrm{mL}-\mathrm{COP}$ and $\mathrm{mL}$ CHOP protocols. Dogs, which were still alive at the time of the analysis or had been lost to follow up, were censored for the survival analysis. The correlation of immunophenotype, treatment, clinical stage, substage, hPARR result and Lasparaginase treatment with clinical outcomes was analysed by Cox regression. The association of clinical response with the MRD result was assessed by Pearson's chi-square test. The SPSS 22 Statistics for Windows software (IBM, USA) was used for all analyses, and significance was accepted at the $\mathrm{P}<0.05$ level.

\section{Results}

\section{Signalment}

The signalment data are shown in Table 3. Pure breeds were mainly Golden/ Labrador retriever (eight dogs) and Shih Tzu (eight dogs). At the first presentation, thrombocytopenia (platelet count less than $160,000 / \mu 1$ ) was reported in six dogs. One dog had anaemia (RBC count less than $5.2 \times 10^{6} \mathrm{cells} / \mu \mathrm{l}$ and a haematocrit volume less than $30 \%$ ). Six dogs had elevated ALT/ALP (values more than $200 \mathrm{IU} / \mathrm{L}$ ). One dog had elevated creatinine and BUN (values of more than 1.4 and $27 \mathrm{mg} \%$, respectively). Three patients were infected with Ehrlichia canis: one dog showed elevated serum levels of antibodies to E. canis by the SNAP 4Dx Plus Test (dog no. 8), and two dogs were found positive by blood smear (dogs no. 3 and 11). 
Table 3

The signalment of 35 canine lymphomas

\begin{tabular}{lc}
\hline $\begin{array}{l}\text { Gender } \\
\text { Male }\end{array}$ & 21 \\
Female & 14 \\
\hline Age (years) & $3-13$ (median 8.5$)$ \\
\hline Breed & \\
Pure & 30 \\
Mixed & 5 \\
\hline Clinical stage & \\
III & 19 \\
IV & 12 \\
V & 4 \\
\hline Substage & \\
a & 24 \\
b & 11 \\
\hline
\end{tabular}

\section{Cytopathology, histopathology and immunophenotype}

Four dogs were diagnosed as having multicentric lymphoma based on their cytology due to their condition being unsuitable (too weak) for general anaesthesia. Their cytological assessments by the updated Kiel criteria were one small lymphocytic lymphoma, one centroblastic monomorphic lymphoma and two centroblastic polymorphic lymphomas. The other 31 dogs were histopathologically classified by examination of the affected LN section using the WHO scheme based on architecture and immunophenotype, as shown in Table 4. In this study, B-cell lymphomas accounted for $80 \%$ (28/35) of the dogs and were categorised as $8.6 \%(3 / 35)$ low grade and $71.4 \%(25 / 35)$ high grade, while T-cell lymphomas accounted for $20 \%(7 / 35)$ of the dogs and were $14.3 \%(5 / 35)$ low grade and $5.7 \%(2 / 35)$ high grade. The most common lymphoma subtypes in dogs were centroblastic diffuse large B-cell lymphoma (DLBCL CB; Fig. 1A) and immunoblastic DLBCL (DLBCL IB). The ICC and IHC results of the B-cell lymphomas showed Pax5+/CD3- (Fig. 1B, C), and T-cell lymphomas were Pax5-/ CD3+ (Fig. 2B, C). However, one case of T-cell rich large B-cell lymphoma (Tcell rich $\mathrm{LBCL}$ ) showed $\mathrm{CD} 3+\mathrm{T}$ cells around large Pax 5+ B cells. 
SIRIVISOOT et al.

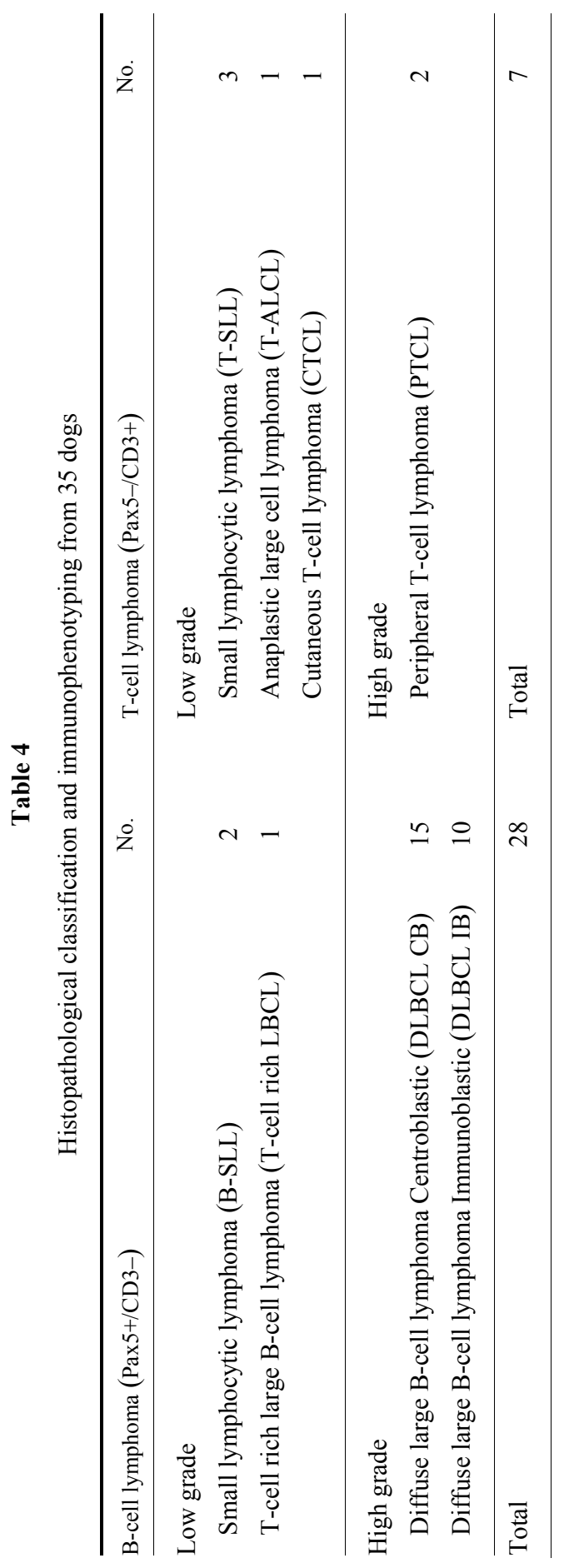



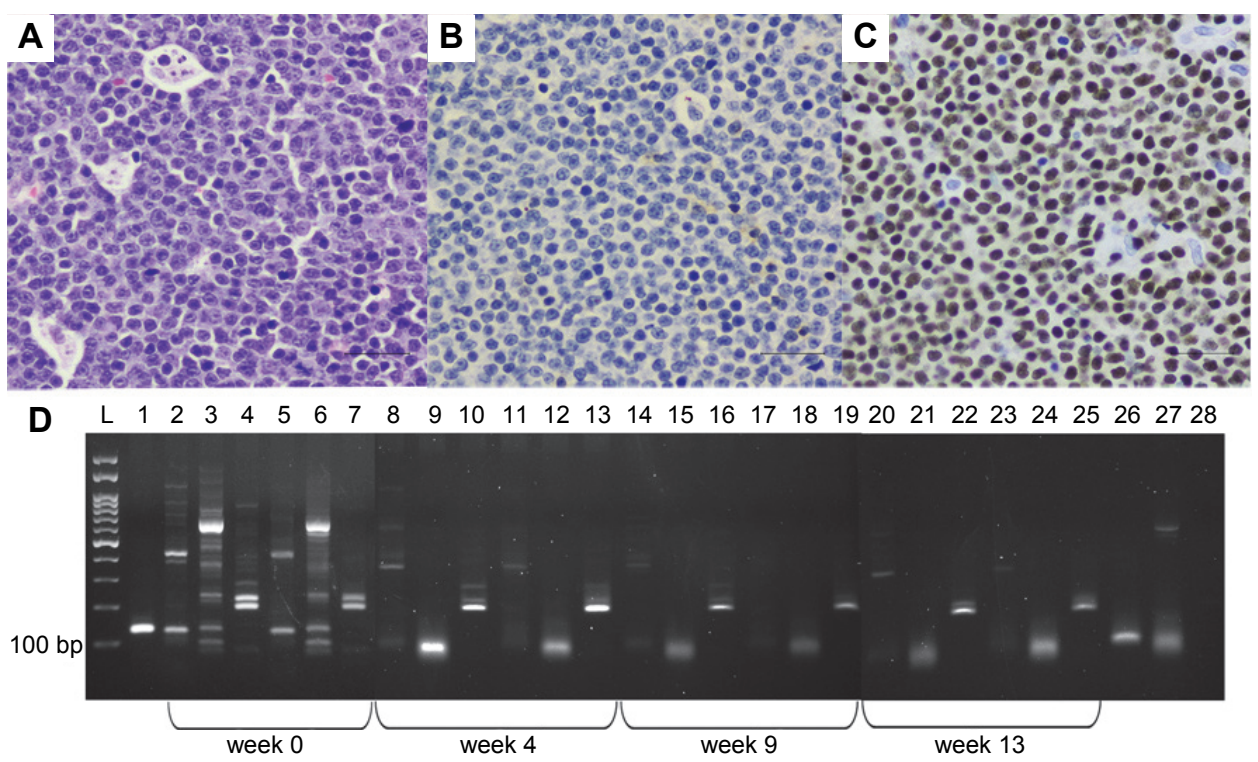

Fig. 1. Diffuse large B-cell lymphoma, high-grade centroblastic type treated with modified mLCHOP. (A) Histopathology showed starry-sky appearance with evidence of tangible-body macrophages. (B) IHC revealed CD3-. (C) Pax5+ immunostained in the nuclei of B cells. Bar $=25 \mu \mathrm{m}$. (D) The hPARR analysis showed monoclonal IgH genes from white blood cell samples in week 0 , and in weeks 4 to 13 a diffuse pattern in both IgH and TCR $\gamma$ genes was evident.

$\mathrm{L}=$ ExcelBand 100 bp ladder; $1=\mathrm{C} \mu$ gene $(130 \mathrm{bp}) ; 2,5,8,11,14,17,20,23=\operatorname{IgH}$ genes $(120 \mathrm{bp})$;

$3,6,9,12,15,18,21,24=$ TCR $\gamma-1$ genes (90 bp); 4, 7, 10, 13, 16, 19, 22, $25=$ TCR $\gamma-2$ gene

(200 bp); 5-7, 11-13, 17-19, 23-25 = heteroduplex analysis; 26 = B-cell lymphoma; 27 = T-cell lymphoma; 28 = negative control

\section{MRD by $h P A R R$}

By hPARR analysis of the 28 B-cell lymphomas, 16 cases presented a clonal band of the IgH gene, eight cases showed TCR $\gamma$ genes (dogs no. 1, 2, 10, $13,16,18,26$, and 27), and four cases (dogs no. 3, 23, 25, and 28) showed dual gene rearrangements. In contrast, $6 / 7$ cases of $\mathrm{T}$-cell lymphomas showed a clonal band of the TCR $\gamma$ gene and one (dog no. 31) showed both IgH and TCR $\gamma$ genes (Table 5). Sensitivity and specificity of the $\operatorname{IgH}$ primer sets were $57.1 \%$ and $100 \%$, respectively, while the TCR $\gamma$ primer sets had $85.7 \%$ sensitivity and $66.7 \%$ specificity. The percentage agreement between the hPARR and the immunophenotyping method was $62.9 \%$.

The mL-COP group consisted of 14 B-cell lymphomas and three T-cell lymphomas, while the mL-CHOP group comprised 14 B-cell lymphomas and four T-cell lymphomas. In the first group, B-cell lymphomas treated with the mL-COP protocol, dog no. 2 showed no response to the treatment and presented hPARR positive in week 9 before PD. Dogs no. 4 and 14 with CR showed 
hPARR positivity during the treatment in week 9 or 13 prior to refractory disease. Dog no. 13 with PR was hPARR positive throughout the treatment before death due to PD. Treatment efficacy of $\mathrm{mL}-\mathrm{COP}$ showed good response in other cases with $\mathrm{CR}$ and no molecular response.
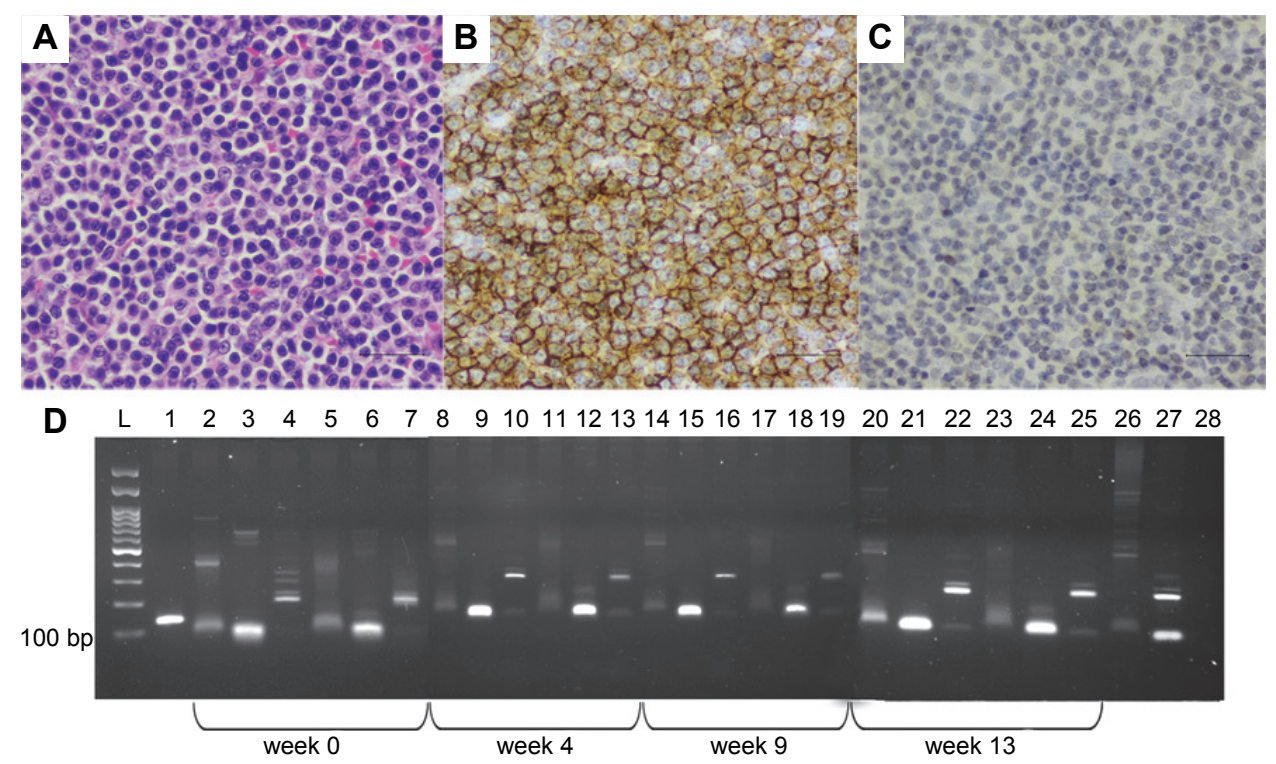

Fig. 2. T-small lymphocytic lymphoma treated with mL-COP. (A) Histopathology presented small neoplastic T cells with cleaved, basophilic nuclei and scant cytoplasm. (B) CD3+ in the cytoplasmic membrane of T cells. (C) Pax5-. Bar $=25 \mu \mathrm{m}$. (D) The hPARR analysis showed a monoclonal TCR $\gamma$ genes from the white blood cell samples in weeks 0 to 13 . $\mathrm{L}=$ ExcelBand 100 bp ladder; $1=\mathrm{C} \mu$ gene $(130 \mathrm{bp}) ; 2,5,8,11,14,17,20,23=\operatorname{IgH}$ genes $(120 \mathrm{bp}) ; 3,6,9,12,15,18,21,24=$ TCR $\gamma-1$ genes (90 bp); 4, 7, 10, 13, 16, 19, 22, 25 = TCR $\gamma-2$ gene (200 bp); 5-7, 11-13, 17-19, 23-25 = heteroduplex analysis; $26=$ B-cell lymphoma; $27=$ T-cell lymphoma; $28=$ negative control

The second group, B-cell lymphoma treated with the mL-CHOP protocol, had only three dogs found hPARR positive whilst receiving the antineoplastic drugs. Dog no. 15 with PR and dog no. 17 with CR had PD and needed a change to a rescue protocol with L-asparaginase and vincristine. However, dog no. 19 with hPARR positivity subsequently had a prolonged OST before death of an unknown cause. The other dogs responded well to the mL-CHOP treatment with no detectable molecular response (Fig. 1D).

In the third group, T-cell lymphomas treated with the mL-COP protocol, dog no. 31 failed to achieve clinical response, showed hPARR positivity before PD and had to be given the rescue drugs. Dogs no. 29 and 30 with CR presented hPARR positive during the treatment, even though they had long PFS or OST (Fig. 2D) similarly to the last group, dog no. 32. 
Table 5

The MRD results by hPARR from four treatment groups with PFS and OST

\begin{tabular}{|c|c|c|c|c|c|c|c|c|}
\hline \multirow{2}{*}{ Group } & \multirow{2}{*}{ Stage } & \multirow{2}{*}{$\begin{array}{l}\text { Re- } \\
\text { sponse }\end{array}$} & \multirow{2}{*}{$\begin{array}{c}\text { Pre- } \\
\text { treatment }\end{array}$} & \multicolumn{3}{|c|}{ Post-treatment } & \multirow{2}{*}{$\begin{array}{l}\text { PFS } \\
\text { (days) }\end{array}$} & \multirow{2}{*}{$\begin{array}{c}\text { OST } \\
\text { (days) }\end{array}$} \\
\hline & & & & Week 4 & Week 9 & Week 13 & & \\
\hline \multicolumn{9}{|l|}{ B-cell lymphoma } \\
\hline \multicolumn{9}{|l|}{ Modified COP } \\
\hline 1. B-SLL & III & $\mathrm{CR}$ & $\mathrm{TCR} \gamma$ & + & - & - & 78 & 126 \\
\hline 2. B-SLL & IV & No & $\mathrm{TCR} \gamma$ & - & + & $\mathrm{R}$ & 70 & 227 \\
\hline 3. T-cell rich LBCL & IV & $\mathrm{CR}$ & Dual & - & - & - & - & $604^{\mathrm{a}}$ \\
\hline 4. DLBCL IB & IV & $\mathrm{CR}$ & $\operatorname{IgH}$ & - & - & + & 103 & 239 \\
\hline 5. DLBCL IB & III & $\mathrm{CR}$ & $\mathrm{IgH}$ & - & - & - & 236 & 371 \\
\hline 6. DLBCL CB & III & $\mathrm{CR}$ & $\mathrm{IgH}$ & - & - & - & - & 144 \\
\hline 7. DLBCL CB & III & PR & $\operatorname{IgH}$ & - & - & - & 24 & 123 \\
\hline 8. DLBCL CB & III & $\mathrm{CR}$ & $\mathrm{IgH}$ & - & - & - & - & 84 \\
\hline 9. DLBCL IB & III & $\mathrm{CR}$ & $\mathrm{IgH}$ & - & - & - & 327 & $548^{\mathrm{b}}$ \\
\hline 10. DLBCL CB & IV & $\mathrm{CR}$ & $\mathrm{TCR} \gamma$ & - & - & - & 89 & 91 \\
\hline 11. DLBCL IB & III & $\mathrm{CR}$ & $\operatorname{IgH}$ & - & - & - & 90 & 265 \\
\hline 12. DLBCL CB & III & $\mathrm{CR}$ & $\operatorname{IgH}$ & - & - & - & - & 218 \\
\hline 13. DLBCL CB & $\mathrm{V}$ & PR & $\mathrm{TCR} \gamma$ & + & + & + & 75 & 89 \\
\hline 14. DLBCL CB & III & $\mathrm{CR}$ & $\operatorname{IgH}$ & - & + & + & 69 & 93 \\
\hline \multicolumn{9}{|l|}{ Modified CHOP } \\
\hline 15. DLBCL IB & IV & PR & $\operatorname{IgH}$ & - & + & + & 34 & 116 \\
\hline 16. DLBCL IB & III & $\mathrm{CR}$ & $\mathrm{TCR} \gamma$ & - & - & - & - & $826^{\mathrm{a}}$ \\
\hline 17. DLBCL CB & IV & $\mathrm{CR}$ & $\operatorname{IgH}$ & - & - & + & 155 & 247 \\
\hline 18. DLBCL CB & IV & $\mathrm{CR}$ & $\mathrm{TCR} \gamma$ & - & - & - & 201 & 247 \\
\hline 19. DLBCL CB & III & $\mathrm{CR}$ & $\mathrm{IgH}$ & + & + & + & - & $338^{\mathrm{b}}$ \\
\hline 20. DLBCL CB & $\mathrm{V}$ & $\mathrm{CR}$ & $\mathrm{IgH}$ & - & - & - & 224 & 286 \\
\hline 21. DLBCL IB & $\mathrm{V}$ & $\mathrm{CR}$ & $\operatorname{IgH}$ & + & - & - & 143 & 245 \\
\hline 22. DLBCL CB & III & $\mathrm{CR}$ & $\operatorname{IgH}$ & - & - & - & 215 & 238 \\
\hline 23. DLBCL CB & III & $\mathrm{CR}$ & Dual & + & + & - & 389 & 585 \\
\hline 24. DLBCL CB & III & $\mathrm{CR}$ & $\operatorname{IgH}$ & - & - & - & 169 & 432 \\
\hline 25. DLBCL IB & IV & $\mathrm{CR}$ & Dual & - & - & - & - & 161 \\
\hline 26. DLBCL IB & IV & $\mathrm{CR}$ & $\mathrm{TCR} \gamma$ & - & - & - & 130 & 159 \\
\hline 27. DLBCL IB & III & $\mathrm{CR}$ & $\mathrm{TCR} \gamma$ & - & - & - & 420 & $597^{\mathrm{a}}$ \\
\hline 28. DLBCL CB & III & $\mathrm{CR}$ & Dual & - & - & - & 341 & 486 \\
\hline \multicolumn{9}{|l|}{ T-cell lymphoma } \\
\hline \multicolumn{9}{|l|}{ Modified COP } \\
\hline 29. T-SLL & III & $\mathrm{CR}$ & $\mathrm{TCR} \gamma$ & + & + & + & 450 & $862^{\mathrm{a}}$ \\
\hline 30. T-SLL & $\mathrm{V}$ & $\mathrm{CR}$ & $\mathrm{TCR} \gamma$ & + & + & + & - & 118 \\
\hline 31. T-ALCL & IV & No & Dual & + & $\mathrm{R}$ & $\mathrm{n} / \mathrm{a}$ & 35 & 171 \\
\hline \multicolumn{9}{|l|}{ Modified CHOP } \\
\hline 32. T-SLL & III & $\mathrm{CR}$ & $\mathrm{TCR} \gamma$ & + & + & + & - & $527^{\mathrm{a}}$ \\
\hline 33. CTCL & III & CR & $\mathrm{TCR} \gamma$ & + & + & - & - & $569^{\mathrm{a}}$ \\
\hline 34. PTCL & IV & CR & $\mathrm{TCR} \gamma$ & - & - & - & 227 & 272 \\
\hline 35. PTCL & IV & CR & $\mathrm{TCR} \gamma$ & - & - & - & 103 & 173 \\
\hline
\end{tabular}

$\mathrm{CR}=$ complete remission; $\mathrm{PR}=$ partial remission; $\mathrm{PFS}=$ progression-free survival; OST $=$ overall survival time; $\mathrm{R}=$ relapse; $\mathrm{B}$ - or T-SLL $=\mathrm{B}$ - or T-small lymphocytic lymphoma; $\mathrm{T}$-cell rich $\mathrm{LBCL}=\mathrm{T}$-cell rich large B-cell lymphoma; DLBCL IB = diffuse large B-cell lymphoma immunoblastic; DLBCL CB = diffuse large B-cell lymphoma centroblastic; T-ALCL = anaplastic large T-cell lymphoma; CTCL = cutaneous T-cell lymphoma; PTCL = peripheral T-cell lymphoma; ${ }^{\mathrm{a}}$ still alive; ${ }^{\mathrm{b}}$ lost to follow-up 


\section{Treatment response and survival time}

The overall response rate to $\mathrm{mL}-\mathrm{COP}$ treatment was $88 \%$ : 13 dogs had CR and two dogs had PR. Two of the 17 dogs had no response. Conversely, the overall response rate to the mL-CHOP treatment was 100\%: 17 dogs had CR and one dog had PR. Two dogs that failed to achieve a CR (dogs no. 2 and 31) had a PFS of 70 and 35 days, respectively, with MRD positivity. Three dogs that had a PR (dogs no. 7, 13 and 15) had a PFS of 24, 75 and 34 days, respectively, and presented hPARR positive before refractory disease. Six dogs were still alive during the time of analysis and two dogs had been lost for contact (Table 5). The treatment response was correlated with the MRD result; cases with $\mathrm{CR}$ to the treatment tended to be MRD negative ( $\mathrm{P}=0.03$, Chi-square test). However, seven dogs with CR showed MRD positivity before current treatment failure.

\section{Table 6}

Variables by univariable analysis as prognosis for PFS and OST in 35 dogs

\begin{tabular}{|c|c|c|c|c|}
\hline Parameter & $\begin{array}{l}\text { Median PFS } \\
\text { (days) }\end{array}$ & $P$ value & $\begin{array}{l}\text { Median OST } \\
\text { (days) }\end{array}$ & $P$ value \\
\hline \multicolumn{5}{|l|}{ Immunophenotype } \\
\hline B-cell (28) & 155 & \multirow[t]{2}{*}{0.213} & 239 & \multirow[t]{2}{*}{0.303} \\
\hline T-cell (7) & 227 & & 272 & \\
\hline \multicolumn{5}{|l|}{ Substage } \\
\hline A (24) & 215 & \multirow[t]{2}{*}{0.002} & 247 & \multirow[t]{2}{*}{0.068} \\
\hline B (11) & 90 & & 173 & \\
\hline \multicolumn{5}{|l|}{ Clinical stage } \\
\hline III (19) & 236 & \multirow[t]{3}{*}{0.060} & 432 & \multirow[t]{3}{*}{0.040} \\
\hline IV (12) & 103 & & 173 & \\
\hline $\mathrm{V}(4)$ & 118 & & 118 & \\
\hline \multicolumn{5}{|l|}{ Minimal residual disease } \\
\hline Present (11) & 103 & \multirow[t]{2}{*}{0.518} & 227 & \multirow[t]{2}{*}{0.618} \\
\hline Absent (24) & 201 & & 247 & \\
\hline \multicolumn{5}{|l|}{ L-asparaginase } \\
\hline With L-asparaginase (21) & 155 & \multirow[t]{2}{*}{0.574} & 245 & \multirow[t]{2}{*}{0.955} \\
\hline Without L-asparaginase (14) & 169 & & 238 & \\
\hline \multicolumn{5}{|l|}{ Treatment } \\
\hline mL-COP (17) & 93 & \multirow[t]{2}{*}{0.034} & 171 & \multirow[t]{2}{*}{0.090} \\
\hline mL-CHOP (18) & 215 & & 272 & \\
\hline
\end{tabular}

The B-cell lymphoma dogs treated with the $\mathrm{mL}-\mathrm{COP}$ protocol had a median PFS of 90 days (95\% CI of 82.7 and 97.3 days) and a median OST of 114 days ( $95 \% \mathrm{CI}$ of 0 and 312.7 days), whereas those treated with the mL-CHOP 
had a median PFS of 201 days (95\% CI of 116.7 and 285.3 days) and a median OST of 247 days (95\% CI of 196.9 and 297.1 days). The T-cell lymphoma dogs treated with the mL-COP had a median PFS of 118 days (95\% CI of 0 and 250.8 days) and a median OST of 171 days (95\% CI of 86.2 and 255.8 days), while those treated with mL-CHOP had a median PFS of 227 days and a median OST 272 days. Both B-cell and T-cell lymphomas treated with the CHOP protocol had longer median PFS $(\mathrm{P}=0.04$; Log-Rank test $)$ and OST $(\mathrm{P}=0.08$; Log-Rank test) than those receiving the COP-based protocol. By immunophenotyping, Bcell lymphomas had a median PFS of 155 days (95\% CI of 121.3 and 188.7 days) and a median OST of 239 days (95\% CI of 218.3 and 259.7 days), while T-cell lymphomas had a median PFS of 227 days (95\% CI of 0 and 506.7 days) and a median OST of 272 days (95\% CI of 17.9 and 526.1 days) with no statistical significance in the PFS ( $\mathrm{P}=0.213$; Log-Rank test $)$ or OST $(\mathrm{P}=0.3$; Log-Rank test $)$.

When compared to other variables (Table 6), which affected the median PFS or OST, substage a had a significantly longer median PFS than substage $b$ by both Log-Rank test (Fig. 3A) and Cox regression. The mL-CHOP also had a prolonged median PFS compared to the mL-COP by Log-Rank test (Fig. 3B). Clinical stage III had a significantly higher OST than the other stages by both Log-Rank test (Fig. 4) and Cox regression.
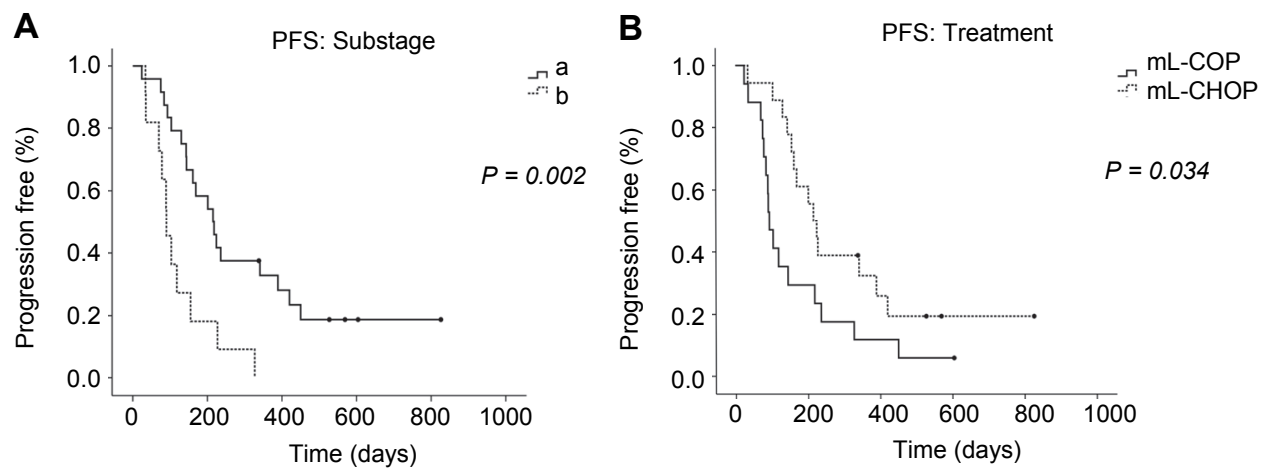

Fig. 3. Kaplan-Meier analysis of (A) substage and (B) treatment effects on progression-free survival (PFS). Black circles indicate censored patients

\section{Discussion}

This study applied hPARR to monitor MRD during treatment for detecting refractory lymphoma. There was a good response to treatment in dogs with hPARR-negative and untraceable LNs, while hPARR positivity was associated with PR or PD. The rescue drugs or a secondary protocol, such as lomustine, doxorubicin or the second shot of L-asparaginase, were given in refractory cases. Three T-cell lymphomas were hPARR positive during the treatment even though 
they had a CR. Therefore, in the case of neoplastic T-cell clones the molecular result and LN measurement should be interpreted concurrently. In our study, peripheral blood leukocytes at diagnosis showed clonal bands, which is dissimilar to the findings of previous studies (Lana et al., 2006; Aresu et al., 2014; HiyoshiKanemoto et al., 2016). However, we used different primer sets, which might affect the sensitivity and specificity of the assay. In addition, this study classified clinical staging based on the blood smear technique instead of bone marrow biopsy. We used the blood smear technique to detect lymphoblasts. If the sample had more than $50 \%$ of lymphoblasts, the dog was classified into clinical stage V. This indicates a stage migration from clinical stage III/IV to stage $\mathrm{V}$ due to hPARR positivity in all white blood cell samples (Flory et al., 2007).

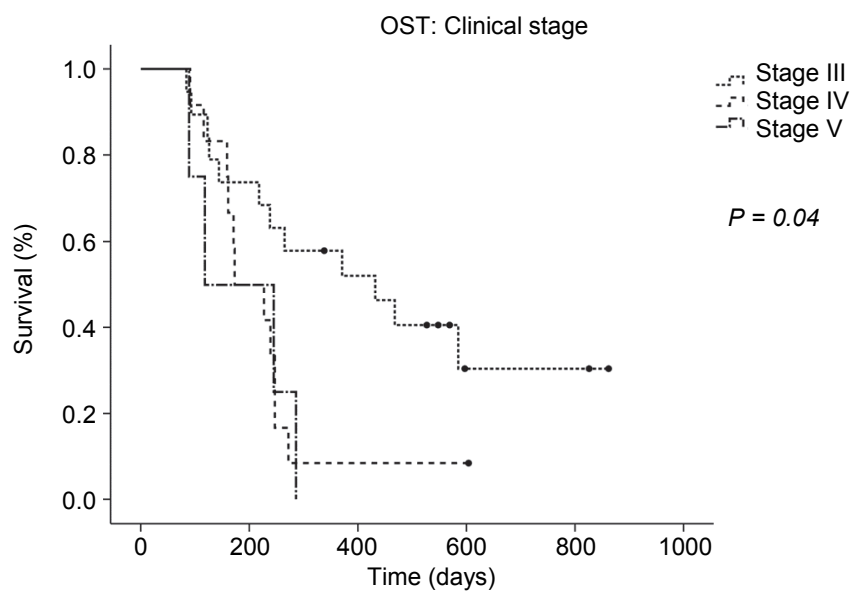

Fig. 4. Kaplan-Meier analysis represents the clinical stage that affected the prognosis of overall survival time (OST). Black circles indicate censored patients

PARR analysis can be used for either diagnosis or MRD detection with suitable primers against the IgH and TCR $\gamma$ genes (Tamura et al., 2006; Yagihara et al., 2007). A few difficulties were observed in the interpretation of results. One of them was the disagreement of immunophenotyping data and monoclonality from leucocyte samples in week 0 . Even though the primer sets of the $\mathrm{IgH}$ genes designed by Tamura et al. (2006) showed 100\% sensitivity and specificity in their study, the sample size was small. Our study found that this primer pair had a sensitivity of $57.1 \%$. However, we detected genes from peripheral blood leucocytes, while they used fine needle aspiration from LN. The TCR $\gamma$ primer sets from Yagihara et al. (2007) represented a T-cell clonal assay in this study. According to their result, we only chose the primer sets of V $\gamma \mathrm{a}-J \gamma b$ and $V \gamma b-J \gamma b$. Our study reported a dissimilar sensitivity and specificity to theirs, but this may reflect experimental differences since they analysed clonal TCR $\gamma$ gene rear- 
rangements from LNs and resolved the amplicons on 7.5\% polyacrylamide gels. One study compared the visualising of PCR products by methods of TCR $\gamma$ gene rearrangement. They found that agarose gel analysis had lower sensitivity than polyacrylamide gel and Genescan analysis (Costa et al., 2004). Different tumour cellularity between the peripheral blood leucocytes and LN samples could decrease the sensitivity of the primers. During the treatment, antineoplastic drugs killed the tumour cells, and so the enlarged LNs became smaller and contained necrotic tumour cells that were not suitable for the extraction of genomic DNA. Therefore, peripheral blood was more suitable for assessing MRD at the end of treatment by PARR (Aresu et al., 2014). Secondly, the product size of the monoclonal band of $\mathrm{V} \gamma \mathrm{b}-\mathrm{J} \gamma \mathrm{b}$ should be in the 55-90 bp size range, but in our study it was observed at $200 \mathrm{bp}$. After DNA sequencing, the amplicons were found to have $100 \%$ nucleotide identity to canine TCR $\gamma$ chain (FR828700.1), ruling out false and nonspecific amplicons. Moreover, another study reported that the product size of V $\gamma \mathrm{b}$ or the V5-2 region was 140-190 bp (Keller et al., 2012). Lastly, some leucocyte samples during the remission phase (weeks 9 and 13) presented a monoclonal pattern of TCR $\gamma$ genes. This could be due to the upregulation of normal T-cell population or to chemo-resistant T-cell lymphoma clones (Calzolari et al., 2006).

Even though PARR is a sensitive method for clonal recognition, pseudoclonality is an impediment due to the immunological diversity of IgH and TCR $\gamma$ genes (Takanosu et al., 2010). Therefore, heteroduplex analysis was helpful to denature and renature polyclonal populations from the real monoclonal population. In our study, pseudoclones after heteroduplex analysis appeared as faint bands as reported before (Takanosu et al., 2010). However, duplicate or triplicate bands can increase the reliability of the result if they are performed concurrently with the heteroduplex analysis, but it is more laborious and costly. Rather, capillary electrophoresis and gene scanning have been shown to be more advantageous in recent studies (Gentilini et al., 2009; Keller and Moore, 2012; GotoKoshino et al., 2015).

Dogs with lymphoma showed a lower relapse rate after doxorubicin administration than after vincristine and cyclophosphamide (Wang et al., 2016). Our study compared treatment efficacy between the mL-COP and mL-CHOP protocols using MRD detection with hPARR. However, due to the high variations and low sample sizes of B- and T-cell lymphoma groups for subsets, no meaningful differences could be demonstrated between the COP and the CHOP protocols by univariate and multivariate analysis.

Fourteen dogs did not receive L-asparaginase for the first treatment in this study ( $8 \mathrm{~mL}$, COP B-cell lymphoma, $5 \mathrm{~mL}$, CHOP B-cell lymphoma, and $1 \mathrm{~mL}$, COP T-cell lymphoma). In most cases (nine dogs), the owners rejected this drug because of its high cost, and in a few cases (five dogs) the dog had abnormal blood results at the time of first diagnosis, so vincristine without L-asparaginase 
was applied as the first therapy. Four out of the 21 (19\%) dogs treated with Lasparaginase and vincristine showed neutropenia, which resulted in delayed treatment. There was no difference in median PFS and OST between treatments with and without L-asparaginase in both the COP and CHOP protocols, in accordance with previous studies (Northrup et al., 2002; MacDonald et al., 2005). One study observed the efficacy of L-asparaginase combined with CHOP and its toxicity. The minimal toxic effects were leukopenia and particularly neutropenia (neutrophils less than 1,500 cells/ $\mu \mathrm{l}$ ). L-asparaginase administered concurrently with vincristine might cause myelosuppression because L-asparaginase decreases the hepatic clearance of vincristine and increases its toxicity (Northrup et al., 2002). Other adverse events were gastrointestinal signs. Moreover, there was no advantageous response to L-CHOP treatment over CHOP (MacDonald et al., 2005). Also, comparison between COP and L-COP for the treatment of lymphoma in 76 dogs revealed that L-COP treatment did not increase the clinical remission or prolong the progression-free interval compared to COP treatment (Jeffreys et al., 2005). According to our observation, both B- and T-cell lymphomas responded well to the first dose of L-asparaginase given concurrently with vincristine, as LN size decreased by more than $75 \%$.

In conclusion, MRD detection from peripheral blood leucocytes by hPARR might be beneficial in the clinical practice for determining refractory lymphomas during the treatment. Because of the painless sampling method, it should be used concurrently with LN measurement as an indicator of treatment failure. In addition, the L-CHOP protocol tended to be a suitable treatment of both multicentric B- and T-cell lymphomas as it could prolong PFS and OST in dogs.

\section{Acknowledgements}

This study was supported by the $90^{\text {th }}$ Anniversary of Chulalongkorn University Fund (Ratchadaphiseksomphot Endowment Fund). SS was supported from the Chulalongkorn University Graduate Scholarship to commemorate the $72^{\text {nd }}$ anniversary of the birthday of his Majesty King Bhumibol Adulyadej.

\section{References}

Aresu, L., Arico, A., Ferraresso, S., Martini, V., Comazzi, S., Riondato, F., Giantin, M., Dacasto, M., Guadagnin, E., Frayssinet, P., Rouquet, N., Drigo, M. and Marconato, L. (2014): Minimal residual disease detection by flow cytometry and PARR in lymph node, peripheral blood and bone marrow, following treatment of dogs with diffuse large B-cell lymphoma. Vet. J. 200, 318-324.

Burnett, R. C., Vernau, W., Modiano, J. F., Olver, C. S., Moore, P. F. and Avery, A. C. (2003): Diagnosis of canine lymphoid neoplasia using clonal rearrangements of antigen receptor genes. Vet. Pathol. 40, 32-41. 
Burton, J. H., Garrett-Mayer, E. and Thamm, D. H. (2013): Evaluation of a 15-week CHOP protocol for the treatment of canine multicentric lymphoma. Vet. Comp. Oncol. 11, 306-315.

Calzolari, C., Gentilini, F., Agnoli, C., Zannoni, A., Peli, A., Cinotti, S. and Bergamini, P. F. (2006): PCR assessment of minimal residual disease in 8 lymphoma-affected dogs. Vet. Res. Commun. 30, 285-288.

Costa, C., Gallardo, F., Pujol, R. M., Espinet, B., Bellosillo, B., Estrach, T., Servitje, O., Barranco, C., Serrano, S. and Sole, F. (2004): Comparative analysis of TCR-gamma gene rearrangements by Genescan and polyacrylamide gel-electrophoresis in cutaneous T-cell lymphoma. Acta Derm. Venereol. 84, 6-11.

Curran, K. and Thamm, D. H. (2016): Retrospective analysis for treatment of naive canine multicentric lymphoma with a 15-week, maintenance-free CHOP protocol. Vet. Comp. Oncol. 14, Suppl. 1, 147-155.

Dobson, J. M., Blackwood, L. B., McInnes, E. F., Bostock, D. E., Nicholls, P., Hoather, T. M. and Tom, B. D. (2001): Prognostic variables in canine multicentric lymphosarcoma. J. Small Anim. Pract. 42, 377-384.

Flory, A. B., Rassnick, K. M., Stokol, T., Scrivani, P. V. and Erb, H. N. (2007): Stage migration in dogs with lymphoma. J. Vet. Intern. Med. 21, 1041-1047.

Garrett, L. D., Thamm, D. H., Chun, R., Dudley, R. and Vail, D. M. (2002): Evaluation of a 6month chemotherapy protocol with no maintenance therapy for dogs with lymphoma. J. Vet. Intern. Med. 16, 704-709.

Gentilini, F., Calzolari, C., Turba, M. E., Bettini, G. and Famigli-Bergamini, P. (2009): GeneScanning analysis of $\mathrm{Ig} / \mathrm{TCR}$ gene rearrangements to detect clonality in canine lymphomas. Vet. Immunol. Immunopathol. 127, 47-56.

Gentilini, F., Turba, M. E. and Forni, M. (2013): Retrospective monitoring of minimal residual disease using hairpin-shaped clone specific primers in B-cell lymphoma affected dogs. Vet. Immunol. Immunopathol. 153, 279-288.

Goto-Koshino, Y., Mochizuki, H., Sato, M., Nakashima, K., Hiyoshi, S., Fujiwara-Igarashi, A., Maeda, S., Nakamura, K., Uchida, K., Fujino, Y., Ohno, K. and Tsujimoto, H. (2015): Construction of a multicolor GeneScan analytical system to detect clonal rearrangements of immunoglobulin and $\mathrm{T}$ cell receptor genes in canine lymphoid tumors. Vet. Immunol. Immunopathol. 165, 81-87.

Hiyoshi-Kanemoto, S., Goto-Koshino, Y., Fukushima, K., Takahashi, M., Kanemoto, H., Uchida, K., Fujino, Y., Ohno, K. and Tsujimoto, H. (2016): Detection of circulating tumor cells using GeneScan analysis for antigen receptor gene rearrangements in canine lymphoma patients. J. Vet. Med. Sci. 78, 877-881.

Jeffreys, A. B., Knapp, D. W., Carlton, W. W., Thomas, R. M., Bonney, P. L., Degortari, A. and Lucroy, M. D. (2005): Influence of asparaginase on a combination chemotherapy protocol for canine multicentric lymphoma. J. Am. Anim. Hosp. Assoc. 41, 221-226.

Keller, S. M. and Moore, P. F. (2012): A novel clonality assay for the assessment of canine T cell proliferations. Vet. Immunol. Immunopathol. 145, 410-419.

Keller, R. L., Avery, A. C., Burnett, R. C., Walton, J. A. and Olver, C. S. (2004): Detection of neoplastic lymphocytes in peripheral blood of dogs with lymphoma by polymerase chain reaction for antigen receptor gene rearrangement. Vet. Clin. Pathol. 33, 145-149.

Lana, S. E., Jackson, T. L., Burnett, R. C., Morley, P. S. and Avery, A. C. (2006): Utility of polymerase chain reaction for analysis of antigen receptor rearrangement in staging and predicting prognosis in dogs with lymphoma. J. Vet. Intern. Med. 20, 329-334.

MacDonald, V. S., Thamm, D. H., Kurzman, I. D., Turek, M. M. and Vail, D. M. (2005): Does Lasparaginase influence efficacy or toxicity when added to a standard CHOP protocol for dogs with lymphoma? J. Vet. Intern. Med. 19, 732-736.

Manachai, N., Lacharoje, S., Techangamsuwan, S. and Rungsipipat, A. (2012): Detection of minimal residual disease (MRD) in canine lymphoma. Comp. Clin. Path. 23, 199-204. 
Northrup, N. C., Rassnick, K. M., Snyder, L. A., Stone, M. S., Kristal, O., Cotter, S. M. and Moore, A. S. (2002): Neutropenia associated with vincristine and L-asparaginase induction chemotherapy for canine lymphoma. J. Vet. Intern. Med. 16, 570-575.

Pott, C., Schrader, C., Gesk, S., Harder, L., Tiemann, M., Raff, T., Bruggemann, M., Ritgen, M., Gahn, B., Unterhalt, M., Dreyling, M., Hiddemann, W., Siebert, R., Dreger, P. and Kneba, M. (2006): Quantitative assessment of molecular remission after high-dose therapy with autologous stem cell transplantation predicts long-term remission in mantle cell lymphoma. Blood 107, 2271-2278.

Sapierzynski, R., Micun, J., Jagielski, D. and Jurka, P. (2010): Cytopathology of canine lymphomas (100 cases). Pol. J. Vet. Sci. 13, 653-659.

Sato, M., Yamzaki, J., Goto-Koshino, Y., Takahashi, M., Fujino, Y., Ohno, K. and Tsujimoto, H. (2013): The prognostic significance of minimal residual disease in the early phases of chemotherapy in dogs with high-grade B-cell lymphoma. Vet. J. 195, 319-324.

Sirivisoot, S., Techangamsuwan, S., Tangkawattana, S. and Rungsipipat, A. (2017): Pax5 as a potential candidate marker for canine B-cell lymphoma. Vet. Med. (Praha) 62, 74-80.

Takanosu, M., Tadika, T. and Kobayashi, T. (2010): Heteroduplex polymerase chain reaction is essential for canine receptor rearrangement analysis. J. Vet. Diagn. Invest. 22, 760-763.

Tamura, K., Yagihara, H., Isotani, M., Ono, K., Washizu, T. and Bonkobara, M. (2006): Development of the polymerase chain reaction assay based on the canine genome database for detection of monoclonality in B cell lymphoma. Vet. Immunol. Immunopathol. 110, 163-167.

Thilakaratne, D. N., Mayer, M. N., MacDonald, V. S., Jackson, M. L., Trask, B. R. and Kidney, B. A. (2010): Clonality and phenotyping of canine lymphomas before chemotherapy and during remission using polymerase chain reaction (PCR) on lymph node cytologic smears and peripheral blood. Can. Vet. J. 51, 79-84.

Vail, D. M., Michels, G. M., Khanna, C., Selting, K. A., London, C. A. and Veterinary Cooperative Oncology Group (2010): Response evaluation criteria for peripheral nodal lymphoma in dogs (v1.0)-a Veterinary Cooperative Oncology Group (VCOG) consensus document. Vet. Comp. Oncol. 8, 28-37.

Valli, V. E., San Myint, M., Barthel, A., Bienzle, D., Caswell, J., Colbatzky, F., Durham, A., Ehrhart, E. J., Johnson, Y., Jones, C., Kiupel, M., Labelle, P., Lester, S., Miller, M., Moore, P., Moroff, S., Roccabianca, P., Ramos-Vara, J., Ross, A., Scase, T., Tvedten, H. and Vernau, W. (2011): Classification of canine malignant lymphomas according to the World Health Organization criteria. Vet. Pathol. 48, 198-211.

Wang, S. L., Lee, J. J. and Liao, A. T. (2016): Assessment of temporal association of relapse of canine multicentric lymphoma with components of the CHOP protocol: Is cyclophosphamide the weakest link? Vet. J. 213, 87-89.

Yagihara, H., Tamura, K., Isotani, M., Ono, K., Washizu, T. and Bonkobara, M. (2007): Genomic organization of the T-cell receptor gamma gene and PCR detection of its clonal rearrangement in canine T-cell lymphoma/leukemia. Vet. Immunol. Immunopathol. 115, 375-382.

Yamazaki, J., Baba, K., Goto-Koshino, Y., Setoguchi-Mukai, A., Fujino, Y., Ohno, K. and Tsujimoto, H. (2008): Quantitative assessment of minimal residual disease (MRD) in canine lymphoma by using real-time polymerase chain reaction. Vet. Immunol. Immunopathol. 126, 321-331.

Yashima, A., Maesawa, C., Uchiyama, M., Tarusawa, M., Satoh, T., Satoh, M., Enomoto, S., Sugawara, K., Numaoka, H., Murai, K., Utsugisawa, T., Ishida, Y. and Masuda, T. (2003): Quantitative assessment of contaminating tumor cells in autologous peripheral blood stem cells of B-cell non-Hodgkin lymphomas using immunoglobulin heavy chain gene allelespecific oligonucleotide real-time quantitative-polymerase chain reaction. Leuk. Res. 27, 925-934.

Zandvliet, M., Teske, E., Schrickx, J. A. and Mol, J. A. (2015): A longitudinal study of ABC transporter expression in canine multicentric lymphoma. Vet. J. 205, 263-271. 